\title{
Rapid soil organic carbon decomposition in river systems: effects of the aquatic microbial community and hydrodynamical disturbance
}

\author{
Man Zhao, Liesbet Jacobs, Steven Bouillon, and Gerard Govers \\ Department of Earth and Environmental Sciences, KU Leuven, 3001 Leuven, Belgium \\ Correspondence: Man Zhao (man.zhao@kuleuven.be) \\ Received: 13 July 2020 - Discussion started: 5 August 2020 \\ Revised: 14 January 2021 - Accepted: 19 January 2021 - Published: 3 March 2021
}

\begin{abstract}
Different erosion processes deliver large amounts of terrestrial soil organic carbon (SOC) to rivers. Mounting evidence indicates that a significant fraction of this SOC, which displays a wide range of ages, is rapidly decomposed after entering the river system. The mechanisms explaining this rapid decomposition of previously stable SOC still remain unclear. In this study, we investigated the relative importance of two mechanisms that possibly control SOC decomposition rates in aquatic systems: (i) in the river water SOC is exposed to the aquatic microbial community which is able to metabolize SOC much more quickly than the soil microbial community and (ii) SOC decomposition in rivers is facilitated due to the hydrodynamic disturbance of suspended sediment particles. We performed different series of short-term $(168 \mathrm{~h})$ incubations quantifying the rates of SOC decomposition in an aquatic system under controlled conditions. Organic carbon decomposition was measured continuously through monitoring dissolved $\mathrm{O}_{2}$ (DO) concentration using a fiber-optic sensor (FireStingO ${ }_{2}$, PyroScience). Under both shaking and standing conditions, we found a significant difference in decomposition rate between SOC with aquatic microbial organisms added (SOC + AMO) and without aquatic microbial organisms (SOC - AMO). The presence of an aquatic microbial community enhanced the SOC decomposition process by $70 \%-128 \%$ depending on the soil type and shaking-standing conditions. While some recent studies suggested that aquatic respiration rates may have been substantially underestimated by performing measurement under stationary conditions, our results indicate that the effect of hydrodynamic disturbance is relatively minor, under the temperature conditions, for the soil type, and for the suspended matter concentration range used in our experiments. We propose a simple conceptual model explaining these contrasting results.
\end{abstract}

\section{Introduction}

Rivers play an important role in the global carbon cycle by linking terrestrial and aquatic ecosystems. Each year, rivers receive and deliver large amounts of terrestrial organic carbon to the oceans (Raymond and Bauer, 2001; Ward et al., 2017). However, rivers do not just transport OC. In 2007, Cole et al. (2007) published the idea of "rivers as an active pipe", which highlights the fact that rivers not only transport but also process large amounts of OC. Mounting evidence indicates that a significant fraction of the OC processed in rivers is soil organic carbon (SOC), including dissolved (DOC) and particulate (POC) forms. The mobilized SOC can display a very wide range of ages among rivers depending on the carbon sources and retention time. Many studies have demonstrated that the DOC transported by large rivers such as the Amazon and Mississippi is generally quite young (Mayorga et al., 2005; Rosenheim et al., 2013), while in other systems the POC is often associated with relatively old radiocarbon ages (in the range of 1000-5000 years BP) (Marwick et al., 2015; Raymond and Bauer, 2001; Dodds and Cole, 2007; McCallister and Del Giorgio, 2012). Several studies have shown that when SOC is delivered to a river, part of this SOC can be rapidly mineralized and emitted back to the atmosphere (Lapierre et al., 2013; Wilkinson et al., 2013; Mayorga et al., 2005). Understanding the mechanisms that contribute to this active mineralization process of SOC is essential for understanding the role of rivers in the global carbon cycle and for assessing how the metabolism of rivers may respond to environmental perturbations such as an increase or decrease in terrestrial carbon delivery to the river system and/or changes in hydrology and climate. Indeed, the amount of SOC imported into riverine ecosystems is often large compared to the autochthonous within-river primary 
production (Cole and Caraco, 2001). It is therefore important to understand the fate of this terrestrial SOC as this not only affects the global carbon cycle but also strongly regulates the ecological functioning of river ecosystems (Kling, 1995). A key question is then which factors control the decomposition of terrestrial SOC, which has been stable in soil for decades to centuries, when it enters into a river system.

In recent years, the mechanisms controlling this rapid riverine mineralization process have gained increasing attention (Aufdenkampe et al., 2011; Guenet et al., 2014; Ward et al., 2017). While in transit, SOC can be degraded by microbial mineralization (Ward et al., 2013) and photochemical oxidation (Spencer et al., 2009). As can be expected, these processes are closely associated with a suite of factors such as temperature (Lapierre et al., 2013; Gudasz et al., 2015), the availability of oxygen (Koehler et al., 2012), and the presence and composition of microbial communities (Ward et al., 2019a), along with physical river properties, such as river velocity and hydrodynamic conditions (Ward et al., 2018). For example, Ward et al. (2018) incubated river water and sediment under three rotation regimes to mimic river flow and found that respiration rates in rotating samples were 1.4 (under $0.22 \mathrm{~m} \mathrm{~s}^{-1}$ ) and 2.4 times (under $0.66 \mathrm{~m} \mathrm{~s}^{-1}$ ) higher compared with stationary conditions. Mechanical disturbance can be expected to enhance mineralization because the physical breakup of large particles induced by river water disturbance may increase the accessibility of microbial enzymes to SOC (Lal, 2003; Richardson et al., 2013).

Microbial organisms influence SOC cycling not only via decomposition but also because microbial products are themselves important components of soil organic matter (KögelKnabner, 2002). The interactions of microbial communities and SOC decomposition have been extensively studied in terrestrial ecosystems (Cleveland et al., 2007; Hu et al., 2014; Tian et al., 2016). The interactions between microbes and SOC in aquatic systems had received little attention until recently. Recently, Ward et al. (2019a) illustrated the potential importance of the composition of the aquatic microbial community by showing that mixing the water of two lowland tributaries (the Tapajós and Xingu rivers) and the main Amazon river resulted in enhanced respiration rates, which they attributed to the fact that such mixing resulted in a more diverse microbial community capable of digesting more OC. While these recent studies clearly indicate that different mechanisms do indeed control OC processing in rivers, important knowledge gaps do remain with respect to the specific controls of SOC decomposition by aquatic microbes. One of the reasons for the latter is that, hitherto, very few experiments were carried out with a factorial design allowing the investigation of the relative importance and potential interaction of different individual factors.

The main objective of this study is to shed light on the fate of SOC in river systems by investigating the relative importance of two key mechanisms that were previously suggested to potentially contribute to the rapid decomposition

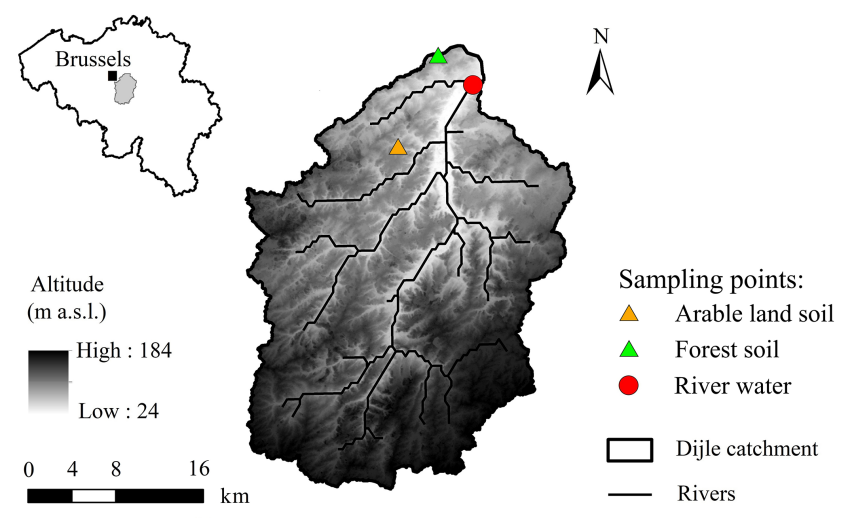

Figure 1. Location of the Dijle catchment and the river water and soil sampling locations.

of previously stable SOC in aquatic systems: (i) in the river water, SOC is exposed to an aquatic microbial community which may be able to metabolize SOC much more quickly than the soil microbial community and (ii) SOC decomposition in rivers may be facilitated due to the hydrodynamic disturbance of sediment. We base our analysis on continuous measurements of DO consumption during a series of lab incubation experiments and the characterization of the evolution of SOC, POC and DOC characteristics throughout the incubation period. By doing so we were able to quantify the importance of these mechanisms both in absolute and relative terms.

\section{Material and methods}

\subsection{Site description}

We sampled the Dijle River located ca. $2 \mathrm{~km}$ upstream of the city of Leuven, which is situated in the central Belgian loess belt (Fig. 1). The relief of the $700 \mathrm{~km}^{2}$ large Dijle River catchment upstream of Leuven varies from about $25 \mathrm{~m}$ above sea level (a.s.l.) in the north to ca. $165 \mathrm{~m}$ a.s.l. in the south. The catchment is characterized by an undulating plateau in which several brooks and rivers are incised. Slope gradients are usually less than $5 \%$, although maximum slopes of ca. $50 \%$ can be found along the valleys. The majority of the soils are Luvisols, developed in the loess deposits (FAO, 1998). The land use in the catchment is mainly cropland, which is particularly vulnerable to erosion during spring and early summer when vegetation cover is low and rainfall intensity is high (Takken et al., 1999). The contemporary land use in the floodplain is dominated by grassland, plantation forests, and built-up area (Broothaerts et al., 2014). 


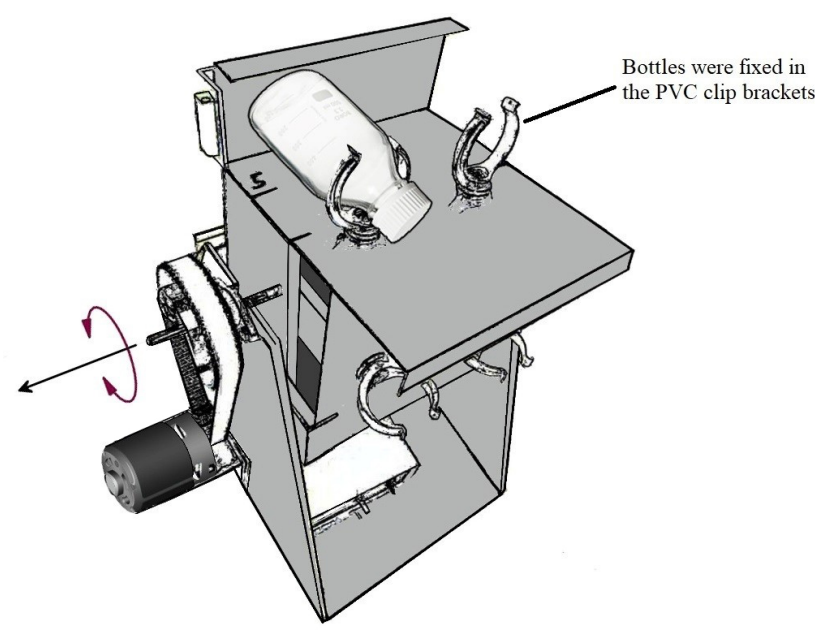

Figure 2. Sketch of the swing system. The swing systems were placed in a temperature-controlled $\left(20^{\circ} \mathrm{C}\right)$ incubation room.

\subsection{Experimental approach}

\subsubsection{Experimental setup}

Our measurement approach involved collecting a large volume of river water, subsequently treated by removing all suspended particles via filtration and dispensing the filtrate into a series of $320 \mathrm{~mL}$ glass incubation bottles. The treatments included (1) SOC with rotation, (2) SOC under stationary conditions, (3) DOC control with rotation, (4) DOC control under stationary conditions, (5) SOC with rotation without AMO, and (6) SOC under stationary conditions without AMO (see Table 1 for details). Mechanical breakup was simulated by a custom-designed swing system (Fig. 2), which kept the particles in suspension during the incubation. Incubation bottles were fixed in the PVC clip brackets and rotated at about seven rounds per minute. Since the bottles were connected with FireSting $\mathrm{O}_{2}$ fiber, the swing system was first rotated $180^{\circ}$ counterclockwise and then $180^{\circ}$ clockwise back, which together was counted as one round. In order to get a higher disturbance intensity, $8 \mathrm{~g}$ of glass beads (diameter: $2 \mathrm{~mm}$ ) were added to the bottle before adding soil and water samples. The glass beads were pre-sterilized at $450^{\circ} \mathrm{C}$ for $1 \mathrm{~h}$ to avoid contamination.

\subsubsection{Collection and incubation}

River water was collected from the Dijle River (details in Table 2). The water was filtered on $0.7 \mu \mathrm{m}$ glass fiber filters to remove all suspended particles. For treatments without aquatic microbial communities, river water was then filtered through $0.2 \mu \mathrm{m}$ syringe filters. Since filtration at $0.7 \mu \mathrm{m}$ already removed the majority of microbial organisms, $4 \mathrm{~mL}$ unfiltered river water (ratio of inoculum to the incubated water sample: $1: 79$ ) was added to serve as an inoculum for treatments with aquatic microbial organisms. Soil sam- ples were collected from the Belgian loess belt near Leuven: one from arable land $\left(50^{\circ} 48^{\prime} 31.6^{\prime \prime} \mathrm{N}, 4^{\circ} 35^{\prime} 16.9^{\prime \prime} \mathrm{E}\right)$, which was collected from a depth of $0-20 \mathrm{~cm}$, and the other from Bertem forest $\left(50^{\circ} 52^{\prime} 59.8^{\prime \prime} \mathrm{N}, 4^{\circ} 38^{\prime} 24.2^{\prime \prime} \mathrm{E}\right)$. The top litter layer was first removed, and then the soil sample was collected from a depth of $0-20 \mathrm{~cm}$. These soils were oven-dried at $\sim 55^{\circ} \mathrm{C}$ and then sieved through $2 \mathrm{~mm}$ to remove all roots and stones. In order to obtain a detectable rate of oxygen consumption, the POC concentration was controlled at 10 $12 \mathrm{mg} \mathrm{L}^{-1}$ by adding $160 \mathrm{mg}$ arable soil and $60 \mathrm{mg}$ forest soil in $320 \mathrm{~mL}$ river water (details in Table 3 ). While the sediment and POC concentrations we used in our experiments are relatively high, they are not unrealistic: during high flood we observed POC concentrations exceeding $10 \mathrm{mg} \mathrm{L}^{-1}$ in ca. $5 \%$ of our samples. The bottles were subsequently closed without headspace. For the suspended condition treatments, bottles were fixed on the swing systems (Fig. 2). The remaining bottles were placed on a shelf to keep particles settled in each bottle. To avoid the influence of temperature and light (both potentially influencing OC mineralization), all bottles were wrapped with aluminum foil and incubated in a temperaturecontrolled room at $\sim 20^{\circ} \mathrm{C}$. For each experiment, four incubation bottles with the same treatment were incubated, which allowed us to sample for POC and DOC during the course of the experiment (at $t=24,48,96,168 \mathrm{~h}$ ). Six experimental runs for each soil type were conducted to investigate the effect of water disturbance and the presence of an aquatic microbial community on SOC decomposition.

Given that the soil samples were oven-dried at $\sim 55^{\circ} \mathrm{C}$ before the incubation, a certain amount of soil microbial organisms might have been eliminated. In order to test this, we carried out a series of supplementary experiments whereby air-dried and oven-dried soil material was used under stationary and rotation conditions. Soil material was collected from the same arable land (OC\%: 1.5\%). The soil was divided into two parts and dried with two methods: one part was oven-dried at $\sim 55^{\circ} \mathrm{C}$, and the other was air-dried. The incubations followed the same procedures mentioned above.

\subsubsection{DO, POC, and DOC measurements}

DO was measured every $10 \mathrm{~s}$ for $168 \mathrm{~h}$ using an optical oxygen meter (FireSting $\mathrm{O}_{2}$ ), and we used the DO data to derive the total amount of $\mathrm{C}$ mineralized in each incubation series, using a procedure similar to the one used in previous studies (Berggren et al., 2012; Richardson et al., 2013). It is known that when $\mathrm{OC}$ is decomposed, the $\mathrm{O}_{2}: \mathrm{CO}_{2}$ ratio is not constant but depends on the composition of the substrate and the characteristics of the bacterial community (Berggren et al., 2012). Richardson et al. (2013) took the elemental composition of organic matter into account and reported an $\mathrm{O}_{2}: \mathrm{CO}_{2}$ ratio of 1.04-1.2 for detrital organic matter and 1.0 for DOC. In this study, we used an $\mathrm{O}_{2}: \mathrm{CO}_{2}$ ratio equal to 1.0 for both SOC and DOC, thus assuming that the mineralization of $1 \mathrm{molC}$ consumed $1 \mathrm{molO}_{2}$. Using a respiration ratio of 
Table 1. Experimental setup for incubations under controlled laboratory conditions.

\begin{tabular}{llll}
\hline $\begin{array}{l}\text { Treatment } \\
\text { number }\end{array}$ & Treatments & $\begin{array}{l}\text { Number of } \\
\text { repetitions }\end{array}$ & Ingredients \\
\hline 1 & SOC, rotation & Six & soil $+0.7 \mu \mathrm{m}$ filtered river water + inoculum \\
2 & SOC, stationary & Six & soil $+0.7 \mu \mathrm{m}$ filtered river water + inoculum \\
3 & DOC control, rotation & Six & $0.7 \mu \mathrm{m}$ filtered river water + inoculum \\
4 & DOC control, stationary & Six & $0.7 \mu \mathrm{m}$ filtered river water + inoculum \\
5 & SOC without AMO, rotation & Six & soil $+0.2 \mu \mathrm{m}$ filtered river water \\
6 & SOC without AMO, stationary & Six & soil $+0.2 \mu \mathrm{m}$ filtered river water \\
\hline
\end{tabular}

Table 2. Nutrient concentrations in the Dijle River water (data from the Flanders Environment Agency: https://www.vmm.be/data/ waterkwaliteit, last access: 13 November 2020).

\begin{tabular}{|c|c|c|c|c|}
\hline Year & $\begin{array}{r}\text { Number of } \\
\text { measurements }\end{array}$ & $\begin{array}{r}\mathrm{NH}_{4}^{+} \\
\left(\mu \mathrm{mol} \mathrm{L}{ }^{-1}\right)\end{array}$ & $\begin{array}{r}\mathrm{NO}_{3}^{-} \\
\left(\mu \mathrm{mol} \mathrm{L}{ }^{-1}\right)\end{array}$ & $\begin{array}{r}\mathrm{PO}_{4}^{3-} \\
\left(\mu \mathrm{mol} \mathrm{L}{ }^{-1}\right)\end{array}$ \\
\hline 2020 & 3 & $24 \pm 7$ & $717 \pm 55$ & no data \\
\hline 2016 & 6 & $48 \pm 30$ & $410 \pm 15$ & $6 \pm 1$ \\
\hline 2014 & 6 & $26 \pm 11$ & $537 \pm 94$ & $6 \pm 1$ \\
\hline
\end{tabular}

Note: values are mean $\pm \mathrm{SD}$.

1.0 might result in an overestimate of the total amount of $\mathrm{C}$ mineralized, but since all treatments were calculated with the same respiration ratio and the same soil samples were used throughout the experiments, the relative variations will not be affected by this choice.

After the incubation period, the entire volume of $\sim 320 \mathrm{~mL}$ water was filtered for later determination of total $\mathrm{POC}$, particulate nitrogen $(\mathrm{PN})$, and the stable $\mathrm{C}$ isotope ratios $\left(\delta^{13} \mathrm{C}\right)$ of POC on pre-combusted $25 \mathrm{~mm}$ Whatman $\mathrm{GF} / \mathrm{F}$ filters (pore size: $0.7 \mu \mathrm{m}$ ). Due to the high concentrations of soil material in each bottle, each water sample was filtered on two to five filter papers. For arable soil incubations, water samples were filtered on five filter papers. We measured all filter papers for two repetitions and two of five filter papers for the other four repetitions. Then we used the suspended sediment weight and POC concentrations measured on this subsample to calculate the POC and PN content as well as the $\delta^{13} \mathrm{C}$ signature of the entire sample. For forest soil incubations, water samples were filtered on two to five filter papers. All of the filter papers were oven-dried at $50^{\circ} \mathrm{C}$ and preserved for POC, $\mathrm{PN}$, and $\delta^{13} \mathrm{C}$ measurements. Inorganic $\mathrm{C}$ was removed from the filters by exposing them to $\mathrm{HCl}$ fumes overnight in a desiccator. Subsequently, the dried filters were packed in Ag cups for analysis on an elemental analyzerisotope ratio mass spectrometer (EA-IRMS, Thermo Finnigan Flash HT and Delta V Advantage). Certified (IAEA-600, caffeine) and in-house laboratory standards (leucine and tuna tissue) were analyzed throughout each run.

To determine the DOC concentration and its stable isotope composition, $40 \mathrm{~mL}$ water samples (filtered at $0.2 \mu \mathrm{m}$ ) were collected and stored in glass vials with Teflon-coated screw caps, and $100 \mu \mathrm{L}$ of $\mathrm{H}_{3} \mathrm{PO}_{4}$ was added for preservation. Analysis of DOC and $\delta^{13} \mathrm{C}_{\mathrm{DOC}}$ was performed on a wet oxidation TOC analyzer (IO Analytical Aurora 1030W) coupled with an isotope ratio mass spectrometer (Thermo Finnigan Delta V Advantage). Quantification and calibration were performed with IAEA-C6 $\left(\delta^{13} \mathrm{C}=-10.4 \%\right)$ and an internal sucrose standard $\left(\delta^{13} \mathrm{C}=-26.99 \pm 0.04 \%\right.$ ) .

The two soil samples used were analyzed for their ${ }^{14} \mathrm{C}$ content on a MICADAS accelerator mass spectrometry system at the Royal Institute for Cultural Heritage (KIK/IRPA, Brussels). Data are reported in years BP, whereby 1950 is taken as the present.

\subsection{Statistical analysis}

Statistical tests were performed in R (version 3.5.1, R Core team). The normality of data was tested with the ShapiroWilk test. The paired sample $t$ test was used to test for differences in DO consumption rates, total amount of $\mathrm{C}$ mineralized, and POC loss between treatments under rotation and stationary conditions as well as to test for differences between treatments with and without the presence of AMO. To identify the combined effect of AMO and physical disturbance on the $\mathrm{C}$ decomposition rates, we used two-way ANOVA with the presence of AMO and mechanical rotation as the main factors. ANOVA was carried out separately for the two soil types. Average values are given \pm the standard deviation.

\section{Results}

\subsection{Effect of water disturbance and AMO on DO consumption rates}

The initial DO concentration in the river water varied from 7.58 to $10.67 \mathrm{mg} \mathrm{L}^{-1}$. In all treatments, DO concentrations followed a decreasing trend, and the DO consumption rates were relatively constant over time (Fig. 3). For incubations where soil was present, cumulative DO consumption ranged between 0.7 and $2.6 \mathrm{mg} \mathrm{L}^{-1}$ during the $168 \mathrm{~h}$ incubation period. The highest DO consumption occurred in the SOC + AMO treatments with average con- 
Table 3. Characteristics of the two soils used in this study. Texture was determined using laser diffraction (Coulter LS 13320 ).

\begin{tabular}{|c|c|c|c|c|c|c|}
\hline \multirow{2}{*}{$\begin{array}{l}\text { Soil samples } \\
\text { Arable soil }\end{array}$} & \multicolumn{2}{|c|}{ Soil texture } & \multirow{2}{*}{$\begin{array}{r}\text { OC content } \\
(\%)\end{array}$} & \multirow{2}{*}{$\begin{array}{r}\mathrm{C} / \mathrm{N} \\
\text { (weight / weight) }\end{array}$} & \multirow{2}{*}{$\begin{array}{r}\delta^{13} \mathrm{C} \\
(\% o)\end{array}$} & \multirow{2}{*}{$\begin{array}{r}{ }^{14} \mathrm{C} \text { age } \\
\text { (year BP) }\end{array}$} \\
\hline & Sand $\%$ & 23 & & & & \\
\hline & Loam \% & 69 & 2.40 & 9.9 & -29.4 & $267 \pm 21$ \\
\hline & Clay \% & 8 & & & & \\
\hline \multirow[t]{3}{*}{ Forest soil } & Sand $\%$ & 39 & & & & \\
\hline & Loam \% & 56 & 5.20 & 17.6 & -28.6 & $334 \pm 22$ \\
\hline & Clay $\%$ & 5 & & & & \\
\hline
\end{tabular}

sumption rates of $0.015 \pm 0.005 \mathrm{mg} \mathrm{O}_{2} \mathrm{~L}^{-1} \mathrm{~h}^{-1}$ (arable soil) and $0.010 \pm 0.002 \mathrm{mg} \mathrm{O}_{2} \mathrm{~L}^{-1} \mathrm{~h}^{-1}$ (forest soil). DO consumption was lowest for treatments where soil was present without AMO with an average of $0.007 \pm 0.002 \mathrm{mg} \mathrm{O}_{2} \mathrm{~L}^{-1} \mathrm{~h}^{-1}$ (arable soil) and $0.004 \pm 0.001 \mathrm{mg} \mathrm{O}_{2} \mathrm{~L}^{-1} \mathrm{~h}^{-1}$ (forest soil). We found that keeping soil particles in suspension resulted in a relatively small acceleration of the OC decomposition process. With the presence of aquatic microbial organisms (SOC $+\mathrm{AMO})$, DO consumption rate was increased on average by $13 \%(p<0.05)$ for the arable soil, while no significant effect was found for forest soil $(p>0.05)$ (Table 4).

The addition of AMO, on the other hand, had a much stronger stimulation effect on OC decomposition. Compared with SOC - AMO treatments, DO consumption rates were approximately doubled by the presence of AMO for both soil types. This increase was present under both rotation (arable soil: $0.015 \pm 0.005$ vs. $0.007 \pm$ $0.002 \mathrm{mg} \mathrm{O}_{2} \mathrm{~L}^{-1} \mathrm{~h}^{-1}, p<0.01$; forest soil: $0.010 \pm 0.002$ vs. $\left.0.005 \pm 0.002 \mathrm{mg} \mathrm{O}_{2} \mathrm{~L}^{-1} \mathrm{~h}^{-1}, p<0.01\right)$ and stationary conditions (arable soil: $0.014 \pm 0.003$ vs. $0.007 \pm$ $0.002 \mathrm{mg} \mathrm{O}_{2} \mathrm{~L}^{-1} \mathrm{~h}^{-1}, p<0.01$; forest soil: $0.009 \pm 0.002 \mathrm{vs}$. $0.004 \pm 0.001 \mathrm{mg} \mathrm{O}_{2} \mathrm{~L}^{-1} \mathrm{~h}^{-1}, p<0.01$ ) (Table 4). In addition, the presence of AMO and rotation had no significant combined effect on the $\mathrm{C}$ decomposition rates for both soil types $(p>0.05)$.

\subsection{Total amount of $\mathrm{C}$ mineralized}

We calculated the total amount of $\mathrm{C}$ mineralized in each treatment, using an $\mathrm{O}_{2}: \mathrm{CO}_{2}$ ratio of 1.0, and expressed mineralization rates on a per carbon basis. Obviously, trends in total $\mathrm{C}$ mineralization are similar to those in oxygen consumption. For SOC + AMO incubations with arable soil, keeping particles in suspension increased the total amount of C mineralized by $13 \%$ ( $p<0.05$, Fig. 4 ). Also, for forest soil a small increase was noted $(11 \%)$, but this was not statistically significant $(p>0.05)$. Compared with SOC $-\mathrm{AMO}$, the presence of aquatic microbial organisms (SOC + AMO) - regardless of soil type and rotating-stationary conditions - significantly stimulated OC decomposition (Fig. 4). For arable soil, AMO addition led to $91 \%$ (under rotation conditions, $p<0.01$ ) to $128 \%$ (under stationary conditions, $p<$ 0.01 ) more $\mathrm{C}$ mineralized by the end of the incubation and $116 \%$ (under rotation conditions, $p<0.01$ ) to $118 \%$ (under stationary conditions, $p<0.01$ ) with forest soil, depending on rotation and stationary conditions.

In addition, when comparing the mineralization of ovendried and air-dried soil without AMO addition, oven-dried soil incubation showed a $40 \%$ lower $\mathrm{C}$ loss in comparison to air-dried soil incubation at the end of the incubation (Fig. 5, $p<0.05)$. However, the addition of AMO resulted in a significantly higher $\mathrm{C}$ loss with both treatments (air drying: $70 \%, p<0.05$; oven drying: $165 \%, p<0.05)$.

\subsection{Particulate and dissolved organic carbon concentrations and $\delta^{13} C_{P O C}$ and $\delta^{13} C_{D O C}$ values}

Measurements of final POC concentrations showed a reduction of POC at the end of the incubations, where 5\%-13\% of POC was mineralized for incubations with arable soil and $1 \%-11 \%$ for incubations with forest soil (Table 4). Keeping particles in suspension resulted in ca. $4 \%$ more POC loss in SOC + AMO incubation series for both soil types, although the increase was only significant for arable soil (arable soil: $13 \%$ vs. $9 \%, p<0.05$; forest soil: $11 \%$ vs. $7 \%$, $p>0.05$, Table 4). Conversely, keeping particles in suspension in SOC - AMO incubation series showed negative effects with 1 (arable soil) to $4 \%$ (forest soil) less POC loss, but this difference was not statistically significant $(p>0.05)$. For both soils, the presence of AMO led to ca. 8\%-10\% more POC loss under rotation conditions $(p<0.05)$. This effect was smaller $(2 \%-3 \%)$ and non-significant $(p>0.05)$ under stationary conditions (Table 4).

These trends are generally consistent with the patterns derived from the oxygen consumption measurements, i.e., a larger reduction in POC when AMO is present and a limited effect of hydrodynamic disturbance on POC decomposition. However, it is also clear that variations in residual POC are less consistent than those observed from oxygen consumption rates. In 7 of 12 incubation series, the combined POC 

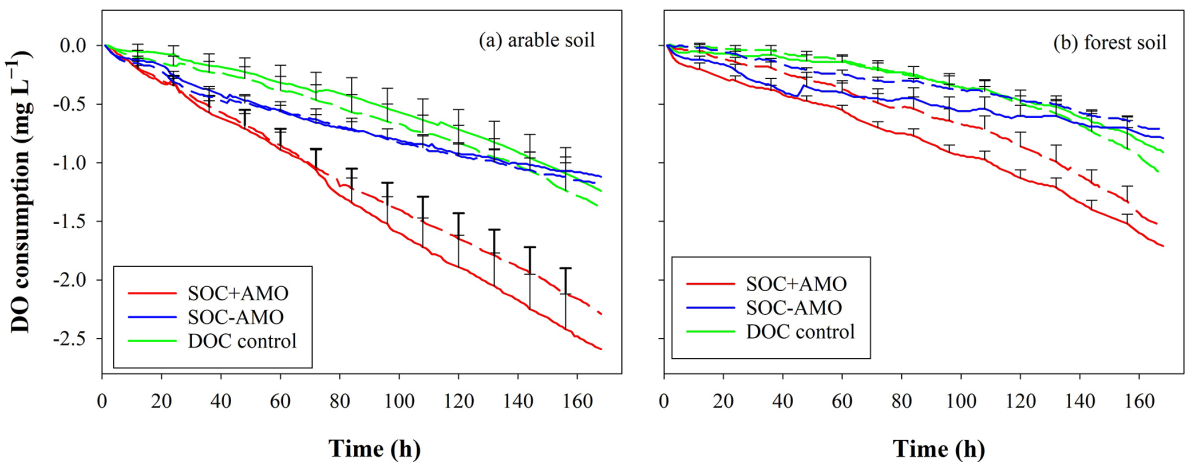

Figure 3. DO consumption of the SOC + AMO treatment (red), the SOC - AMO treatment (blue), and the DOC control treatment (green) during the incubations, under rotating (full lines) and stationary (dashed lines) conditions: (a) incubation with arable soil, (b) incubation with forest soil. Standard errors were calculated based upon six repetitions with different river water samples.
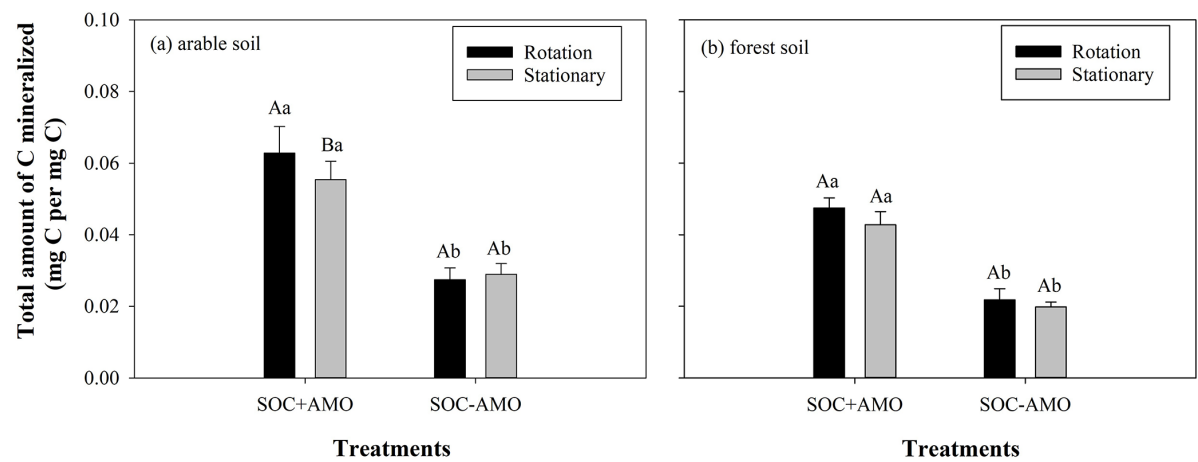

Figure 4. Total amount of $\mathrm{C}$ mineralized during the incubations with and without AMO under rotation and stationary conditions with (a) arable soil and (b) forest soil. Different capital letters indicate significant differences between treatments under rotation and stationary conditions at $p<0.05$; different lowercase letters indicate significant differences between treatments with and without AMO at $p<0.01$.

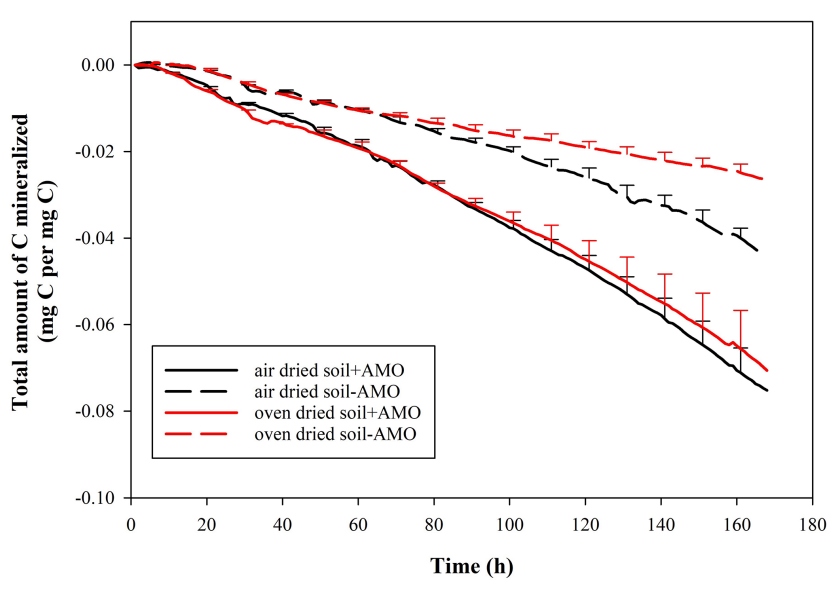

Figure 5. Cumulative amount of $\mathrm{C}$ mineralized during incubation with oven-dried soil (red) and air-dried soil (black), with addition of AMO (full line) and without addition of AMO (dashed line). Standard errors were calculated based upon three repetitions with different river water samples. and DOC losses exceeded the total amount of $\mathrm{C}$ mineralized calculated from DO consumption (Table 4).

Variations in $\delta^{13} \mathrm{C}_{\mathrm{POC}}$ values showed a similar pattern for both soil types (Fig. 6): firstly, an increase in $\delta^{13} \mathrm{C}_{\mathrm{POC}}$ occurred during the first $24 \mathrm{~h}$ (for forest soil) or $48 \mathrm{~h}$ (arable soil). The increase in $\delta^{13} \mathrm{C}_{\mathrm{POC}}$ appears to be more important for forest soil $(0.4 \% 0-0.6 \%$ o $)$ in comparison to arable soil $(0.2 \%$ o $-0.4 \% o)$. After this initial period, $\delta^{13} \mathrm{C}_{\mathrm{POC}}$ values stabilized.

DOC concentrations were relatively stable during the incubation (Fig. 7; Table 4). The initial $\delta^{13} \mathrm{C}_{\mathrm{DOC}}$ value was lower in arable soil experiments where no $\mathrm{AMO}$ was present. When AMO was present the initially higher $\delta^{13} \mathrm{C}_{\mathrm{DOC}}$ values declined to similar values as those observed in experiments without AMO within the first $48 \mathrm{~h}$. In the experiments with forest soil, initial $\delta^{13} \mathrm{C}_{\mathrm{DOC}}$ values were slightly but not significantly higher $(0.6 \%, p>0.05)$ than the initial $\delta^{13} \mathrm{C}_{\mathrm{DOC}}$ values for arable soil without $\mathrm{AMO} . \delta^{13} \mathrm{C}_{\mathrm{DOC}}$ values were stable throughout the incubation period for all forest soil experiments.

For both soil types, the equilibrium $\delta^{13} \mathrm{C}_{\mathrm{DOC}}$ values appear to be somewhat lower than the equilibrium $\delta^{13} \mathrm{C}_{\mathrm{POC}}$ val- 

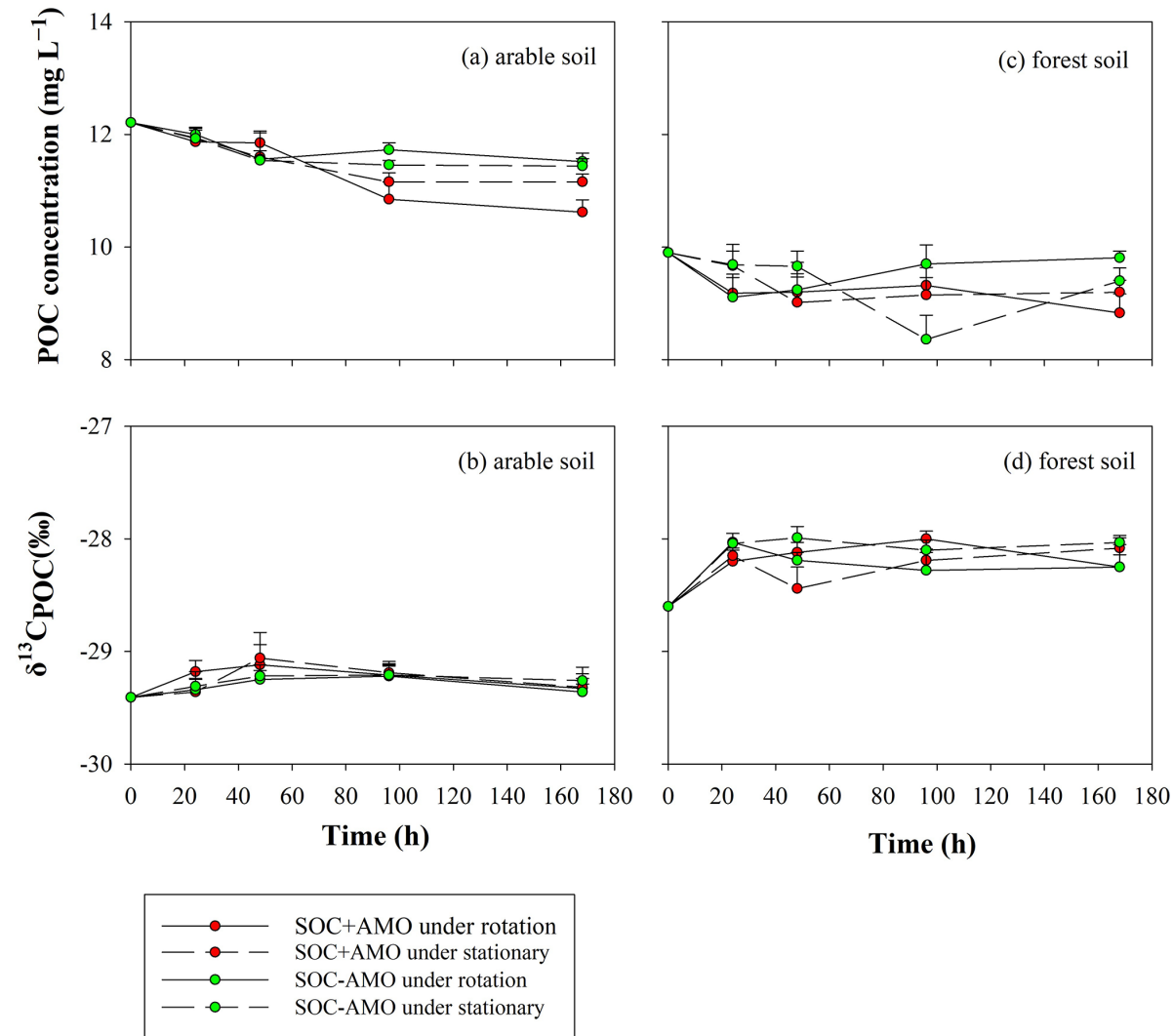

Figure 6. Evolution of POC concentrations and $\delta^{13} \mathrm{C}_{\mathrm{POC}}$ values during the incubations for the arable soil (a, b, respectively) and the forest soil (c, d, respectively).

ues: this difference was more pronounced for the forest soil (ca. $1 \%$ in comparison to ca. $0.5 \%$ on average), but nonsignificant in both cases $(p>0.05)$.

\section{Discussion}

Our results show that a fraction of the terrestrial SOC can indeed be mineralized relatively quickly when introduced in an aquatic environment. With the presence of aquatic microbial organisms (SOC + AMO), up to 0.58 (forest soil) or 0.97 (arable soil) $\mathrm{mg} \mathrm{CL}^{-1}$ was mineralized within the $168 \mathrm{~h}$ incubation period, equivalent to $83-139 \mu \mathrm{g} \mathrm{C} \mathrm{L}^{-1} \mathrm{~d}^{-1}$ or 9-12 $\mu \mathrm{g} \mathrm{C}(\mathrm{mg} \mathrm{SOC})^{-1} \mathrm{~d}^{-1}$. Comparable respiration rates of $20-80 \mu \mathrm{g} \mathrm{C} \mathrm{L}^{-1} \mathrm{~d}^{-1}$ were reported under similar temperature conditions by Berggren et al. (2010). Similar incubation experiments with water samples collected from northern temperate lakes and streams reported respiration rates from 16 to $54 \mu \mathrm{g} \mathrm{C} \mathrm{L}-1 \mathrm{~d}^{-1}$ (McCallister and Del Giorgio, 2012). We found that $C$ mineralization rates were quite significant: in the presence of an AMO (which is always the case in natural conditions), $4 \%$ to $6 \%$ of the OC present at the initiation of the experiment was mineralized during the experiment (Fig. 4). Typical soil incubation experiments show a loss of max. $2 \%$ of the SOC in the first 2 weeks:
Gillabel et al. (2010) incubated soil samples under $25^{\circ}$ and found ca. $2 \%$ SOC was respired in $20 \mathrm{~d}$ with a mineralization rate at around $1 \mu \mathrm{g} \mathrm{C} \mathrm{mg} \mathrm{C}{ }^{-1} \mathrm{~d}^{-1}$; Angst et al. (2019) conducted a similar soil incubation and found a cumulative

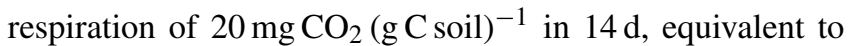
around $0.4 \mu \mathrm{g} \mathrm{C} \mathrm{mg} \mathrm{C} \mathrm{C}^{-1} \mathrm{~d}^{-1}$. Li et al. (2018) incubated soil with fertilization and straw application and found highest cumulative respiration at around $800 \mathrm{mg} \mathrm{CO}_{2}-\mathrm{C} \mathrm{kg}^{-1}$ soil in $20 \mathrm{~d}$, equivalent to around $2 \mu \mathrm{g} \mathrm{Cmg} \mathrm{C}-1 \mathrm{~d}^{-1}$. Thus mineralization rates observed in soil incubation experiment $(0.4-$ $2 \mu \mathrm{g} \mathrm{C} \mathrm{mg} \mathrm{C}-1 \mathrm{~d}^{-1}$ ) are much lower than those observed in our study, where 6-9 $\mu \mathrm{g} \mathrm{C}$ is mineralized per milligram of $\mathrm{C}$ per day. This suggests that SOC indeed decomposes 510 times more rapidly in aquatic systems than in the terrestrial environment and that SOC is not as recalcitrant as preciously thought in aquatic systems (Mayorga et al., 2005; McCallister and Del Giorgio, 2012). Several studies already suggested that the transition from terrestrial to aquatic conditions likely facilitated SOC decomposition rates because of shifts in environmental conditions (Butman and Raymond, 2011; McCallister and Del Giorgio, 2012). In soils, sorption of OC to mineral surfaces and encapsulation of $\mathrm{C}$ within soil aggregates may protect SOC from complete mineralization (Bianchi et al., 2011; Schmidt, et al., 2011). This results in 

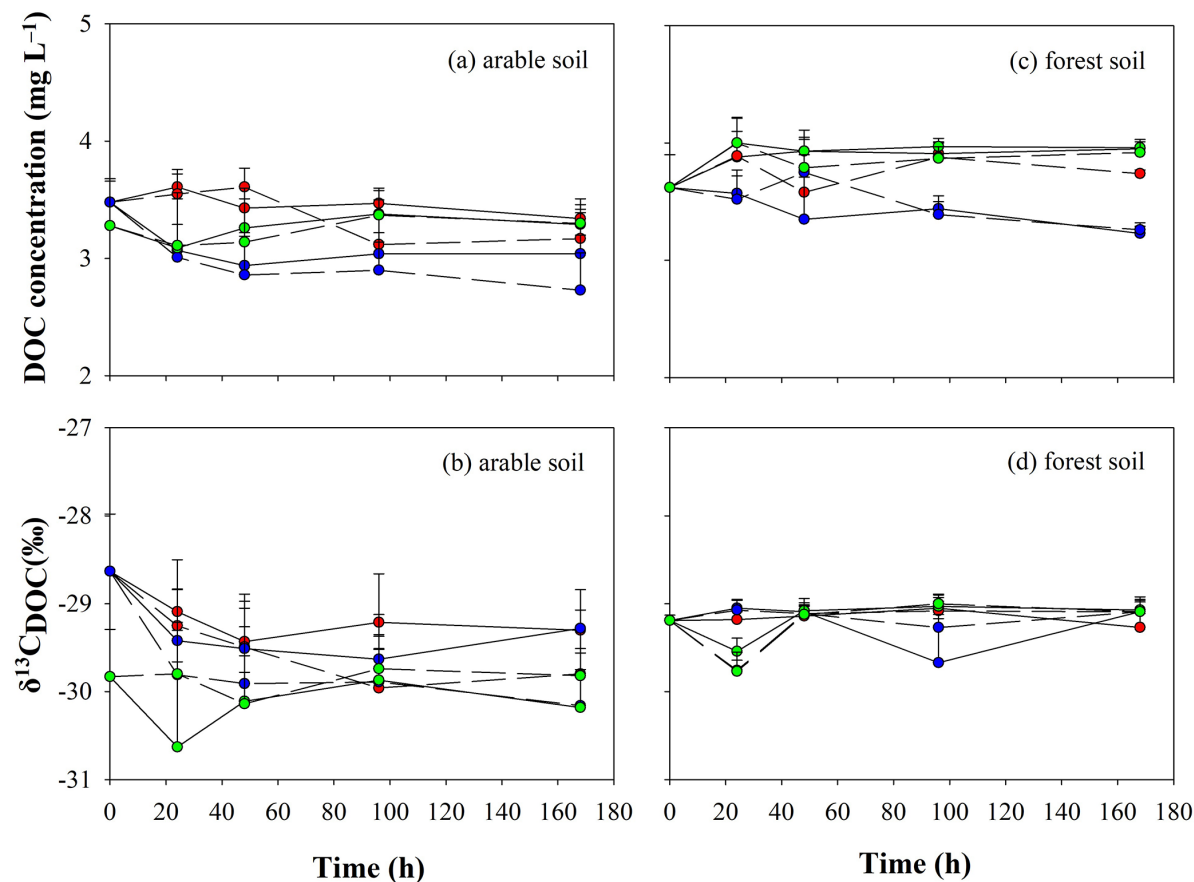

Time (h)

Time (h)

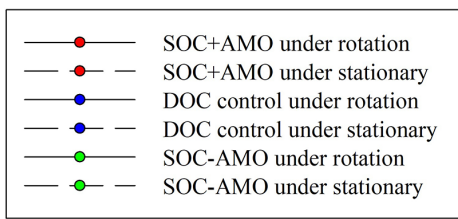

Figure 7. Evolution of DOC concentrations and $\delta^{13} \mathrm{C}_{\mathrm{DOC}}$ values during the incubations for the arable soil (a, b, respectively) and the forest soil (c, d, respectively).

the accumulation of older SOC in pools that are less accessible to decomposers and their extracellular enzymes (MarínSpiotta et al., 2014). When SOC enters aquatic systems, a disruption of the mechanisms protecting $\mathrm{C}$ from mineralization, such as a physical disturbance due to the physical action of transport in water but also due to aggregate slaking (Le Bissonnais, 1996), may lead to the exposure of these protected pools to decomposers and therefore to an increase in the SOC decomposition rate. Alternatively, SOC decomposition may be accelerated due to the fact that, in an aquatic environment, a population of possible consumers is present that is different from that in the soil and that may be capable of rapidly mineralizing SOC that is otherwise preserved over long timescales in a soil environment (Wu et al., 2018; Ward et al., 2019b).

Our results indicate that physical soil disturbance, which was simulated by rotation in our experiments, had a relatively minor effect on SOC decomposition (arable soil: $p<0.05$; forest soil: $p>0.05$ ) (Figs. 3, 4). This result is different from that reported in two previous studies with similar incubation approaches. Richardson et al. (2013) and Ward et al. (2018) found that keeping sediment particles in suspension increased river-borne organic matter decomposition by
$40 \%$ to $140 \%$, depending on the rotation speed. The differences in experimental settings, such as POC composition, POC concentration, and microbial community may influence the POC decomposition rates (Weyhenmeyer et al., 2012; Ward et al., 2019a). However, these differences as such do not explain the minor effect of physical disturbance observed in this study. Thus, our data do indicate that the relative role of physical disturbance vs. that of exposure to an aquatic microbial community may vary considerably between different ecosystems. We propose two possible reasons as to why we did not find a strong effect of physical disturbance on SOC decomposition. It is hypothetically possible that the level of physical protection of (a large part of) the SOC that is present is such that it is not disrupted by the physical disturbance that we imposed. Alternatively, the level of physical protection was so weak that the mere immersion of soil particles in water was sufficient to destroy most of it. Given the fact that loess soils are known for their very low structural stability (Le Bissonnais, 1996) and the high POC mineralization rates we observed, we propose that the latter is more likely in our experiments. The results of our last series of experiments (Fig. 5) also show that when SOC is introduced into an aquatic environment where no aquatic microbial commu- 
nity is present, there is also a significant degree of SOC decomposition. Again, this suggests that the simple immersion into water results in the breakdown of the physical protection of SOC, so that a similar microbial community becomes much more effective in decomposing SOC in an aqueous rather than a soil environment. We found that mineralization rates of forest SOC were lower than those of arable land SOC (Fig. 4). Forest soils often have a relatively stronger structural stability associated with a higher SOC content (Göl, 2009; Gajic et al., 2006). If the lower mineralization rates of forest SOC were indeed due to a higher structural stability of the forest soil aggregates, one would therefore expect that mechanical disturbance would have a stronger effect on SOC mineralization for the forest soil. However, the effect of mechanical disturbance is small and statistically insignificant, also for the forest soil. Therefore, it seems more likely that the difference in response we observed between the two SOC types is due to differences in the composition of the organic matter in both soils. The forest SOC has a much higher $\mathrm{C} / \mathrm{N}$ ratio, which is generally associated with a lower decomposability (Liang et al., 2017).

The presence of an aquatic microbial community caused a much more rapid mineralization of SOC (Figs. 3, 4). In all experimental runs that we performed $(n=24)$, there was a significant difference between treatments with and without aquatic microbial organisms $(p<0.01)$. Given that the soil samples were oven-dried at $\sim 55^{\circ}$ before the incubation, the effect of inoculation with AMO may at least partly be explained by the fact that the soil microbial community was killed by the drying process. Comparing the results of ovendried and air-dried soil without AMO addition, it is clear that oven drying indeed led to a $40 \%$ decrease in the total amount of $\mathrm{C}$ mineralized in comparison to air-dried soil, indicating that oven drying indeed eliminated an important fraction of OC-consuming soil microbial organisms (Fig. 5). However, the addition of AMO resulted in clearly higher $\mathrm{C}$ losses with both soil treatments (air drying: ca. $70 \%$; oven drying: ca. $165 \%$ ), indicating that aquatic microorganisms indeed have the capacity to rapidly consume SOC that is not readily mineralized by soil microorganisms. It is well-known that a significant fraction of the SOC is relatively old (Trumbore, 2000). The presence of such old fractions in the soil suggests that the soil ecosystem contains no or only a very small number of consumers capable of mineralizing this POC fraction. Some consumers in aquatic ecosystems may have the capability to consume this relatively old POC relatively quickly, especially when it is no longer physically protected.

The higher POC consumption rates observed when an AMO is present may, of course, partly be due to the fact that more microbes were present in those experiments where AMO was introduced. We compared the initial population of bacteria with and without the addition of AMO. The addition of AMO led to $20 \%-30 \%$ more bacteria present in the water at the beginning of the experiment (arable soil: $4.30 \times 10^{5}$ vs. $3.52 \times 10^{5}$ cells $\mathrm{mL}^{-1}$; forest soil: $3.67 \times 10^{5}$ vs. $2.86 \times$ 
$10^{5}$ cells $\mathrm{mL}^{-1}$ ). This larger initial population could partly explain the higher SOC decomposition rates with the addition of AMO, but the fact that the addition of AMO increases SOC decomposition rates by $70 \%-165 \%$ rather than $20 \%-$ $30 \%$ does suggest that the aquatic microbial community is indeed capable of attacking old, stable SOC more effectively than the soil microbial community. Although the microbial community is considered to play a central role in shaping OC reactivity in both terrestrial and aquatic systems (Schmidt et al., 2011), such a strong stimulation effect of the addition of AMO on SOC has rarely been reported.

The evolution of POC and DOC concentrations during the experiments is generally in agreement with the patterns derived from the oxygen consumption measurements. However, the variations in residual POC are less consistent than those observed from oxygen consumption. Several reasons might explain the discrepancy between the total $\mathrm{C}$ mineralization as calculated from oxygen consumption in comparison to direct measurements of POC. Firstly, POC and DOC samples were collected from four incubation bottles for one treatment. Even though we controlled the initial conditions of each bottle as closely as possible, there might be heterogeneity between different bottles with respect to the OC content of the soil sample that was placed into the bottle. Secondly, we compared POC measurements from two to five filter papers for arable soil and five filter papers for forest soil. For each individual measurement the filter weight has to be subtracted from the gross weight of the filter plus the sediment. Given the small quantities of sediment present on the filters, small weighing errors will result in relatively large errors in the calculation of the amount of POC that is remaining. DO measurements are non-intrusive and are not subject to measurement errors related to the weighing of small quantities. We therefore believe that the oxygen consumption measurements provide us with more robust measurements of OC decomposition in comparison to direct measurements of the OC content of the remaining sample. The direct measurements suggest that, overall, POC mineralization was more important than DOC mineralization when POC was present. Indeed, DOC concentrations showed little variation during the experiments, despite significant oxygen consumption rates.

The increase in $\delta^{13} \mathrm{C}_{\mathrm{POC}}$ values during the first $24-48 \mathrm{~h}$ suggests that during this period an isotopically lighter POC fraction was preferentially mineralized. This resulted in the POC in the aquatic environment becoming enriched in ${ }^{13} \mathrm{C}$ by $0.2 \% o-0.6 \%$ compared to the POC in the original soil sample. After the initial adjustment period, $\delta^{13} \mathrm{C}_{\mathrm{POC}}$ remained stable, suggesting the initial adjustment is indeed due to the preferential consumption of a somewhat lighter, less recalcitrant $\mathrm{POC}$ fraction rather than continued preferential consumption of lighter POC. The fact that over the whole course of the experiments the $\delta^{13} \mathrm{C}_{\mathrm{DOC}}$ values are lower than the corresponding $\delta^{13} \mathrm{C}_{\mathrm{POC}}$ values is on the other hand best explained by a continuous leaching/release of DOC with a somewhat lower $\delta^{13} \mathrm{C}$ signature from the soil POC, replacing

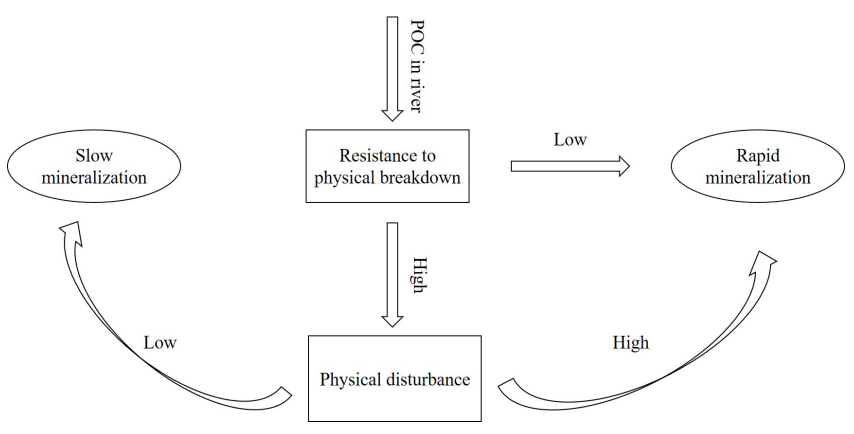

Figure 8. Conceptual figure representing the effect of physical disturbance on SOC decomposition upon entering river water.

the mineralized DOC as it is unlikely that the DOC fraction would be entirely stable while POC is continuously mineralized. Mineralization of the original DOC and its replacement with soil-derived DOC could also explain the drop in $\delta^{13} \mathrm{C}_{\mathrm{DOC}}$ during the initial phase of the experiments with arable soil and AMO, because the lighter DOC that was originally present in the river water is replaced by soil-derived DOC. However, this drop was not observed in the experiments with forest soil. This may be partly explained by the higher $\delta^{13} \mathrm{C}$ value of the forest soil $(-28.6 \%$ ) in comparison to the $\delta^{13} \mathrm{C}$ signature of the arable soil $(-29.4 \%$ ), causing the DOC released from the forest soil to have an isotopic signature close to that of the river water. While the patterns described above would be consistent with the preferential decomposition of isotopically lighter POC, we did not observe an increase in $\delta^{13} \mathrm{C}_{\mathrm{POC}}$ during our experiments as might be expected by the selective mobilization of an isotopically lighter soil fraction: this can be explained by the relatively small differences in $\delta^{13} \mathrm{C}$ values between POC and DOC in combination with the fact that only a small fraction of the POC is ultimately mineralized, whereby most of this mineralized fraction may have been directly transformed to $\mathrm{CO}_{2}$. If this mineralization does not selectively affect specific fractions of the POC pool, the $\delta^{13} \mathrm{C}_{\mathrm{POC}}$ values can be expected to remain more or less constant throughout the incubation period.

Based on our findings, we propose that the relative importance of physical disturbance vs. exposure to a novel microbial community is likely to depend on (i) the level to which the SOC is indeed physically protected and (ii) the extent to which this protection is destroyed by aggregate disruption when soil particles are introduced in river water. When the protection level is relatively important but, at the same time, sensitive to water immersion, further physical disturbance due to transport of soil particles in the river is unlikely to strongly increase SOC breakdown because aggregates are already destroyed when the sediment enters the water. If, on the other hand, physical protection is strong and aggregates are resistant to immersion, physical disturbance may be necessary to break down soil aggregates to the extent that is 
needed to expose a significant fraction of SOC to the microbial community present in water (Fig. 8). The loess-derived soils we used in our experiments do have a weak structure (Govers, 1991), resulting in rapid aggregate breakdown upon immersion in water and a relatively small effect of mechanical disturbance on mineralization rates. This also explains the insignificant interaction effect of hydrodynamic disturbance and the presence of an aquatic microbial community on the $\mathrm{C}$ decomposition rates for both soil types $(p>0.05)$. The mere immersion of soil particles in water is sufficient to destroy most of the soil aggregates. Therefore, further disturbance would not strongly increase the interactions between soil particles and microbial organisms. The effect of the presence of an aquatic microbial community, on the other hand, will depend on its composition and its vigor. The addition of SOC may shift aquatic microbial metabolisms and make it more prone to SOC decomposition (Lennon and Pfaff, 2005). Other factors such as water temperatures and nutrient availability may also play a role. The river water we used in our study has a high nutrient content (Table 2): the availability of a large nutrient pool may allow AMO to use the SOC more effectively and may be one of the factors explaining why we saw such an important increase in SOC decomposition when AMO was added. However, it is fair to state that our current understanding of the interaction between old SOC and different microbial communities is too limited to develop general principles describing which factors may stimulate or slow the decomposition of SOC exposed to a new microbial community.

\section{Conclusions}

We investigated the relative importance of physical disturbance vs. exposure to a novel microbial community for SOC decomposition rates in aquatic environments. While some recent studies found that the impact of mechanical disturbance on SOC decomposition rates was very important, we found only a very modest increase in SOC decomposition when soil particles were mechanically disturbed and kept in suspension. A simple conceptual model, whereby the effect of mechanical disturbance is assumed to depend on the initial structural stability of soil aggregates, can explain this difference in findings: mechanical disturbance is only important when soil aggregates are strong enough to withstand the disruptive forces imposed by immersion in water.

Our study also highlights the role of aquatic microbial organisms in SOC decomposition in river systems. Aquatic microbial organisms are capable of attacking SOC, leading to rapid SOC decomposition in river systems. Given the variability of aquatic microbial community composition in different aquatic systems, understanding the linkage between aquatic microbial community composition and abundance on the one hand and the resultant SOC mineralization rates on the other hand is important not only to better understand $\mathrm{CO}_{2}$ outgassing from aquatic systems, but also to understand how the ecological functioning of rivers and lakes is affected by the large changes in SOC inputs that result from human activities.

Data availability. All data used and produced through this study are available with the Supplement.

Supplement. The supplement related to this article is available online at: https://doi.org/10.5194/bg-18-1511-2021-supplement.

Author contributions. GG, SB, LJ, and MZ were involved in the design of the experiments, and MZ carried out the experiments. SB and MZ conducted the laboratory analysis. All authors offered advice on the data analysis and contributed to the paper preparation.

Competing interests. The authors declare that they have no conflict of interest.

Acknowledgements. We are grateful to Zita Kelemen for help with stable isotope analysis, to Filip Meysman (UA) for his suggestions with respect to experimental design, and to Mathieu Boudin (KIK/IRPA) for radiocarbon measurements. We thank the two anonymous reviewers, whose constructive comments and suggestions greatly improved an earlier version of this paper.

Financial support. This research has been supported by the China Scholarship Council (grant no. 201706300031).

Review statement. This paper was edited by Ji-Hyung Park and reviewed by two anonymous referees.

\section{References}

Angst, G., Mueller, C. W., Prater, I., Angst, Š., Frouz, J., Jílková, V., Peterse, F., and Nierop, K. G. J.: Earthworms act as biochemical reactors to convert labile plant compounds into stabilized soil microbial necromass, Commun. Biol., 2, 1-7, https://doi.org/10.1038/s42003-019-0684-z, 2019.

Aufdenkampe, A. K., Mayorga, E., Raymond, P. A., Melack, J. M., Doney, S. C., Alin, S. R., Aalto, R. E., and Yoo, K.: Riverine coupling of biogeochemical cycles between land, oceans, and atmosphere, Front. Ecol. Environ., 9, 53-60, https://doi.org/10.1890/100014, 2011.

Berggren, M., Laudon, H., Jonsson, A., and Jansson, M.: Nutrient constraints on metabolism affect the temperature regulation of aquatic bacterial growth efficiency, Microb. Ecol., 60, 894-902, https://doi.org/10.1007/s00248-010-9751-1, 2010.

Berggren, M., Lapierre, J. F., and Del Giorgio, P. A.: Magnitude and regulation of bacterioplankton respiratory quotient 
across freshwater environmental gradients, ISME J., 6, 984-993, https://doi.org/10.1038/ismej.2011.157, 2012.

Bianchi, T. S.: The role of terrestrially derived organic carbon in the coastal ocean: A changing paradigm and the priming effect, Proc. Natl. Acad. Sci., 108, 19473-19481, https://doi.org/10.1073/pnas.1017982108, 2011.

Broothaerts, N., Verstraeten, G., Kasse, C., Bohncke, S., Notebaert, B., and Vandenberghe, J.: From natural to humandominated floodplain geoecology - A Holocene perspective for the Dijle catchment, Belgium, Anthropocene, 8, 46-58, https://doi.org/10.1016/j.ancene.2014.12.001, 2014.

Butman, D. and Raymond, P. A.: Significant efflux of carbon dioxide from streams and rivers in the United States, Nat. Geosci., 4, 839-842, https://doi.org/10.1038/ngeo1294, 2011.

Cleveland, C. C., Nemergut, D. R., Schmidt, S. K., and Townsend, A. R.: Increases in soil respiration following labile carbon additions linked to rapid shifts in soil microbial community composition, Biogeochemistry, 82, 229-240, https://doi.org/10.1007/s10533-006-9065-z, 2007.

Cole, J. J. and Caraco, N. F.: Carbon in catchments: Connecting terrestrial carbon losses with aquatic metabolism, Mar. Freshw. Res., 52, 101-110, https://doi.org/10.1071/mf00084, 2001.

Cole, J. J., Prairie, Y. T., Caraco, N. F., McDowell, W. H., Tranvik, L. J., Striegl, R. G., Duarte, C. M., Kortelainen, P., Downing, J. A., Middelburg, J. J., and Melack, J.: Plumbing the global carbon cycle: Integrating inland waters into the terrestrial carbon budget, Ecosystems, 10, 172-185, https://doi.org/10.1007/s10021006-9013-8, 2007.

Dodds, W. K. and Cole, J. J.: Expanding the concept of trophic state in aquatic ecosystems: It's not just the autotrophs, Aquat. Sci., 69, 427-439, https://doi.org/10.1007/s00027-007-0922-1, 2007.

FAO: World Reference Base for Soil Resources, World Soil Resources Reports 84, Food and Agriculture Organization of the United Nations, Rome, https://doi.org/10.1108/09504121011021959, 1998.

Gajic, B., Dugalic, G., and Djurovic, N.: Comparison of soil organic matter content, aggregate composition and water stability of gleyic fluvisol from adjacent forest and cultivated areas, Agron. Res., 4, 499-508, 2006.

Gillabel, J., Cebrian-Lopez, B., Six, J., and Merckx, R.: Experimental evidence for the attenuating effect of SOM protection on temperature sensitivity of SOM decomposition, Glob. Chang. Biol., 16, 2789-2798, https://doi.org/10.1111/j.13652486.2009.02132.x, 2010.

Govers, G.: Rill Erosion on Arable Land in Central Belgium: Rates, Controls and Predictability, Catena, 18, 133-155, https://doi.org/10.1016/0341-8162(91)90013-n, 1991.

Göl, C.: The effects of land use change on soil properties and organic carbon at Dagdami river catchment in Turkey, J. Environ. Biol., 30, 825-830, 2009.

Gudasz, C., Sobek, S., Bastviken, D., Koehler, B., and Tranvik, L. J.: Temperature sensitivity of organic carbon mineralization in contrasting lake sediments, J. Geophys. Res.-Biogeosci., 120, 1215-1225, https://doi.org/10.1002/2015jg002928, 2015.

Guenet, B., Danger, M., Harrault, L., Allard, B., Jauset-Alcala, M., Bardoux, G., Benest, D., Abbadie, L., and Lacroix, G.: Fast mineralization of land-born $\mathrm{C}$ in inland waters: First experimental evidences of aquatic priming effect, Hydrobiologia, 721, 35-44, https://doi.org/10.1007/s10750-013-1635-1, 2014.
Hu, Y., Xiang, D., Veresoglou, S. D., Chen, F., Chen, Y., Hao, Z., Zhang, X., and Chen, B.: Soil organic carbon and soil structure are driving microbial abundance and community composition across the arid and semi-arid grasslands in northern China, Soil Biol. Biochem., 77, 51-57, https://doi.org/10.1016/j.soilbio.2014.06.014, 2014.

Kling, G. W.: Land-water interactions: the influence of terrestrial diversity on aquatic ecosystems, in: Arctic and Alpine Biodiversity: Patterns, Causes and Ecosystem Consequences, edited by: Chapin, F. S. and Körner, C., Springer, Berlin and Heidelberg, Germany, 297-310, https://doi.org/10.1007/978-3-642-78966-3, 1995.

Kögel-Knabner, I.: The macromolecular organic composition of plant and microbial residues as inputs to soil organic matter, Soil Biol. Biochem., 34, 139-162, https://doi.org/10.1016/s00380717(01)00158-4, 2002.

Koehler, B., Von Wachenfeldt, E., Kothawala, D., and Tranvik, L. J.: Reactivity continuum of dissolved organic carbon decomposition in lake water, J. Geophys. Res.-Biogeosci., 117, G01024, https://doi.org/10.1029/2011jg001793, 2012.

Lal, R.: Soil erosion and the global carbon budget, Environ. Int., 29, 437-450, https://doi.org/10.1016/S0160-4120(02)00192-7, 2003.

Lapierre, J. F., Guillemette, F., Berggren, M., and Del Giorgio, P. A.: Increases in terrestrially derived carbon stimulate organic carbon processing and $\mathrm{CO}_{2}$ emissions in boreal aquatic ecosystems, Nat. Commun., 4, 1-7, https://doi.org/10.1038/ncomms3972, 2013.

Le Bissonnais, Y. L.: Aggregate stability and assessment of soil crustability and erodibility: I. Theory and methodology, Eur. J. Soil Sci., 47, 425-437, https://doi.org/10.1111/j.13652389.1996.tb01843.x, 1996.

Lennon, J. T. and Pfaff, L. E.: Source and supply of terrestrial organic matter affects aquatic microbial metabolism, Aquat. Microb. Ecol., 39, 107-119, https://doi.org/10.3354/ame039107, 2005.

Li, J., Wu, X., Gebremikael, M. T., Wu, H., Cai, D., Wang, B., Li, B., Zhang, J., Li, Y., and Xi, J.: Response of soil organic carbon fractions, microbial community composition and carbon mineralization to high-input fertilizer practices under an intensive agricultural system, PLoS One, 13, e0195144, https://doi.org/10.1371/journal.pone.0195144, 2018.

Liang, X., Yuan, J., Yang, E., and Meng, J.: Responses of soil organic carbon decomposition and microbial community to the addition of plant residues with different $\mathrm{C}: \mathrm{N}$ ratio, Eur. J. Soil Biol., 82, 50-55, https://doi.org/10.1016/j.ejsobi.2017.08.005, 2017.

Marín-Spiotta, E., Gruley, K. E., Crawford, J., Atkinson, E. E., Miesel, J. R., Greene, S., Cardona-Correa, C., and Spencer, R. G.: Paradigm shifts in soil organic matter research affect interpretations of aquatic carbon cycling: transcending disciplinary and ecosystem boundaries, Biogeochemistry, 117, 279297, https://doi.org/10.1007/s10533-013-9949-7, 2014.

Marwick, T. R., Tamooh, F., Teodoru, C. R., Borges, A. V, Darchambeau, F., and Bouillon, S.: The age of river-transported carbon: a global perspective, Global Biogeochem. Cy., 29, 122-137, https://doi.org/10.1002/2014gb004911, 2015.

Mayorga, E., Aufdenkampe, A. K., Masiello, C. A., Krusche, A. V., Hedges, J. I., Quay, P. D., Richey, J. E., and Brown, T. A.: Young organic matter as a source of carbon diox- 
ide outgassing from Amazonian rivers, Nature, 436, 538-541, https://doi.org/10.1038/nature03880, 2005.

McCallister, S. L. and Del Giorgio, P. A.: Evidence for the respiration of ancient terrestrial organic $\mathrm{C}$ in northern temperate lakes and streams, Proc. Natl. Acad. Sci., 109, 16963-16968, https://doi.org/10.1073/pnas.1207305109, 2012.

Raymond, P. A. and Bauer, J. E.: Riverine export of aged terrestrial organic matter to the North Atlantic Ocean, Nature, 409, 497500, https://doi.org/10.1038/35054034, 2001.

Richardson, D. C., Newbold, J. D., Aufdenkampe, A. K., Taylor, P. G., and Kaplan, L. A.: Measuring heterotrophic respiration rates of suspended particulate organic carbon from stream ecosystems, Limnol. Oceanogr., 11, 247-261, https://doi.org/10.4319/lom.2013.11.247, 2013.

Rosenheim, B. E., Roe, K. M., Roberts, B. J., Kolker, A. S., Allison, M. A., and Johannesson, K. H.: River discharge influences on particulate organic carbon age structure in the Mississippi/Atchafalaya River System, Global Biogeochem. Cy., 27, 154-166, https://doi.org/10.1002/gbc.20018, 2013.

Schmidt, M. W. I., Torn, M. S., Abiven, S., Dittmar, T., Guggenberger, G., Janssens, I. A., Kleber, M., Kögel-Knabner, I., Lehmann, J., Manning, D. A. C., Nannipieri, P., Rasse, D. P., Weiner, S., and Trumbore, S. E.: Persistence of soil organic matter as an ecosystem property, Nature, 478, 49-56, https://doi.org/10.1038/nature10386, 2011.

Spencer, R. G. M., Stubbins, A., Hernes, P. J., Baker, A., Mopper, K., Aufdenkampe, A. K., Dyda, R. Y., Mwamba, V. L., Mangangu, A. M., Wabakanghanzi, J. N., and Six, J.: Photochemical degradation of dissolved organic matter and dissolved lignin phenols from the Congo River, J. Geophys. Res.-Biogeosci., 114, G03010, https://doi.org/10.1029/2009jg000968, 2009.

Takken, I., Beuselinck, L., Nachtergaele, J., Govers, G., Poesen, J., and Degraer, G.: Spatial evaluation of a physicallybased distributed erosion model (LISEM), Catena, 37, 431-447, https://doi.org/10.1016/s0341-8162(99)00031-4, 1999.

Tian, Q., Yang, X., Wang, X., Liao, C., Li, Q., and Wang, M.: Microbial community mediated response of organic carbon mineralization to labile carbon and nitrogen addition in topsoil and subsoil, Biogeochemistry, 128, 125-139, https://doi.org/10.1007/s10533016-0198-4, 2016.

Trumbore, S.: Age of soil organic matter and soil respiration: Radiocarbon constraints on belowground $\mathrm{C}$ dynamics, Ecol. Appl., 10, 399-411, https://doi.org/10.1890/10510761(2000)010[0399:aosoma]2.0.co;2, 2000.
Ward, N. D., Keil, R. G., Medeiros, P. M., Brito, D. C., Cunha, A. C., Dittmar, T., Yager, P. L., Krusche, A. V., and Richey, J. E.: Degradation of terrestrially derived macromolecules in the Amazon River, Nat. Geosci., 6, 530-533, https://doi.org/10.1038/ngeo1817, 2013.

Ward, N. D., Bianchi, T. S., Medeiros, P. M., Seidel, M., Richey, J. E., Keil, R. G., and Sawakuchi, H. O.: Where Carbon Goes When Water Flows: Carbon Cycling across the Aquatic Continuum, Front. Mar. Sci., 4, 7, https://doi.org/10.3389/fmars.2017.00007, 2017.

Ward, N. D., Sawakuchi, H. O., Neu, V., Less, D. F. S., Valerio, A. M., Cunha, A. C., Kampel, M., Bianchi, T. S., Krusche, A. V., Richey, J. E., and Keil, R. G.: Velocity-amplified microbial respiration rates in the lower Amazon River, Limnol. Oceanogr. Lett., 3, 265-274, https://doi.org/10.1002/lol2.10062, 2018.

Ward, N. D., Sawakuchi, H. O., Richey, J. E., Keil, R. G., and Bianchi, T. S.: Enhanced Aquatic Respiration Associated With Mixing of Clearwater Tributary and Turbid Amazon River Waters, Front. Earth Sci., 7, 1-6, https://doi.org/10.3389/feart.2019.00101, 2019a.

Ward, N. D., Morrison, E. S., Liu, Y., Rivas-Ubach, A., Osborne, T. Z., Ogram, A. V., and Bianchi, T. S.: Marine microbial community responses related to wetland carbon mobilization in the coastal zone, Limnol. Oceanogr. Lett., 4, 25-33, https://doi.org/10.1002/lol2.10101, 2019b.

Weyhenmeyer, G. A., Fröberg, M., Karltun, E., Khalili, M., Kothawala, D., Temnerud, J., and Tranvik, L. J.: Selective decay of terrestrial organic carbon during transport from land to sea, Glob. Change Biol., 18, 349-355, https://doi.org/10.1111/j.13652486.2011.02544.x, 2012.

Wilkinson, G. M., Pace, M. L., and Cole, J. J.: Terrestrial dominance of organic matter in north temperate lakes, Global Biogeochem. Cy., 27, 43-51, https://doi.org/10.1029/2012gb004453, 2013.

Wu, X., Wu, L., Liu, Y., Zhang, P., Li, Q., Zhou, J., Hess, N. J., Hazen, T. C., Yang, W., and Chakraborty, R.: Microbial interactions with dissolved organic matter drive carbon dynamics and community succession, Front. Microbiol., 9, 1234, https://doi.org/10.3389/fmicb.2018.01234, 2018. 